\title{
The effect of the thermal environment on the ability of hatchling Galapagos land iguanas to avoid predation during dispersal. Volume 491981
}

[s.l.]: [s.n.], 1981

https://digital.library.wisc.edu/1711.dl/JCI3EW4KBLDBE8M

This material may be protected by copyright law (e.g., Title 17, US Code).

For information on re-use see:

http://digital.library.wisc.edu/1711.dl/Copyright

The libraries provide public access to a wide range of material, including online exhibits, digitized collections, archival finding aids, our catalog, online articles, and a growing range of materials in many media.

When possible, we provide rights information in catalog records, finding aids, and other metadata that accompanies collections or items. However, it is always the user's obligation to evaluate copyright and rights issues in light of their own use. 


\title{
The Effect of the Thermal Environment on the Ability of Hatchling Galapagos Land Iguanas to Avoid Predation During Dispersal
}

\author{
Keith A. Christian and C. Richard Tracy \\ Department of Zoology and Entomology, Colorado State University, Fort Collins, Colorado 80523, USA
}

\begin{abstract}
Summary. During the month of February 1979, several hundred hatchling land iguanas (Conolophus pallidus) were observed emerging from their natal burrows in a 2 ha communal nesting area on Isla Santa Fe, Galapagos Islands. During this emergence, as many as nine Galapagos hawks were observed to patrol the nesting area and attack hatchling iguanas.

The hypothesis that the ability of hatchling land iguanas to escape predation could be influenced by the interaction of the physiological state of the lizards and the thermal environment was analyzed using (1) empirical data on the effect of body temperature $\left(T_{\mathrm{b}}\right)$ on locomotory ability of iguanas and (2) biophysical modeling of the $T_{\mathrm{b}}$ 's of hatchlings under natural conditions. This hypothesis was tested by assessing the success of natural hawk attacks on lizards exposed to different thermal environments.

During those periods when predicted $T_{\mathrm{b}}$ 's of hatchlings were always $<32^{\circ} \mathrm{C}$, (at which temperatures land iguanas were shown to have less than maximal ability to sprint rapidly) hawks were successful in $67 \%$ of the observed attacks. However, when $T_{\mathrm{b}}$ 's of hatchlings were always $\geqq 32^{\circ} \mathrm{C}$, hawks were successful on only $19 \%$ of observed attacks. During periods when hatchling $T_{\mathrm{b}}$ 's could be $<32^{\circ} \mathrm{C}$ or $32-40^{\circ} \mathrm{C}$ (depending upon which microhabitat the hatchling occupied before the attack), the hawks were successful in $46 \%$ of the observed attacks.

These data indicate that the physical environment, as mediated through the physiological state of the lizards and to correlated locomotary abilities, significantly affects the ability of hatchling land iguanas to escape predation.
\end{abstract}

\section{Introduction}

An attack on prey by a predator is a uniquely clear-cut event in terms of natural selection; the prey either escapes, or is killed (Curio 1976). The direct relationship between predator avoidance and Darwinian fitness dictates that the mechanisms by which prey species escape predation be regarded as fundamentally important to our understanding of ecological and evolutionary principles of predator-prey interactions.

The thermal environment certainly can influence the vulnerability of ectothermic vertebrates to predation (Porter et al. 1973). In a theoretical discussion of lizard thermoregulation. Huey and Slatkin (1976) surmized that the ability to escape predation is "undoubtedly a function of body temperature". Huey and Stevenson (1979) have suggested that measurements of an animal's "performance" (e.g. rate of growth, locomotory ability, reproductive rate and others) over a broad range of body temperatures $\left(T_{\mathrm{b}}\right)$ can be useful in interpreting the ecological consequences of body temperature as a physiological state. For example, Greenwald (1974) has experimentally demonstrated that the velocity of the strike of a gopher snake (Pituophis melanoleucus) and the consequent success of catching prey are directly dependent upon the snake's body temperature.

While no direct measure of the functional relationship between bodytemperature and predator avoidance by an ectotherm has been published, indirect evidence of such a relationship exists. Rand (1964) demonstrated that lizards compensate for suboptimal $T_{\mathrm{b}}$ (presumably suboptimal performance) by increasing the approach distance (i.e. the minimum distance a prey species will permit potential predators to approach before initiating escape). Fox (1978) demonstrated that individual side-blotched lizards, Uta stansburiana, had higher probability of survival under heavy predation when they could exploit conditions of clear skles and warm temperatures. These studies and others (reviewed by Heatwole 1976) provide indirect evidence of a relationship between $T_{\mathrm{b}}$ and ability of lizards to escape predation.

Microclimatic data have been used in conjuction with energy balance models to investigate aspects of predator-prey interactions (Riechert and Tracy 1975; Porter et al. 1973; Porter and Tracy 1974; and Porter et al. 1975). In general. these models have been used to compare the daily and seasonal activity patterns of predators and their prey (each of which can be predicted with respect to "optimum " $T_{\mathrm{b}}$ 's) to predict periods of temporal overlap, during which predation is expected to occur. Empirical data on the modeled systems are lacking, however.

In this study we combine biophysical modeling to predict $T_{\mathrm{b}}$ with empirical data on physiological performance as a function of $T_{\mathrm{b}}$ to predict the ability of a lizard to escape predation. We then compare our predictions with observed results of 128 attacks by the Galapagos hawk (Buteo galapagoensis) on hatchling land iguanas (Conolophus pallidus) at a communal nesting site on Santa Fe (Barrington) Island, Galapagos.

\section{Area and Organisms}

The study was conducted on Isla Santa Fe of the Galapagos Islands. Ecuador. Santa $\mathrm{Fe}$ is a low, uplifted island with an area of 2.413 ha. Tree cactus (Opuntia echios), the Palo Santo tree (Bursera grateolens). and two shrub species (Cordia lutea and Lantama peduncularis) constitute the dominant vegetation over most of the island. There are a few isolated patches on the island characterized by soils of toose red cinders and populated by short (approx. $1 \mathrm{~m}$ tall) shrubs. Euclelia hispida (deVries 1973. and pers. obs.). These areas are used by the female iguanas for nesting. The nesting site was a flat area with relative- 
ly little vegetational cover and essentially no cover in the form of rock crevices that occur virtually everywhere else on the island. By far the dominant vegetation in the nesting area was the shrub Encelia hispida which neither adult nor hatchling were ever observed to eat.

During the course of an extensive study of the land iguana a communal nesting site was discovered. Aggregations of nesting lizards previously have been reported only for a few iguanines (see Wiewand 1980). Approximately 300 female land iguanas were observed nesting in a single area of about 2 ha during October and November 1978. A detailed description of the movements and nesting behavior of female iguanas during 1978 will be presented elsewhere (Christian and Tracy. 1981.

Emergence of hatchlings occurred the February following nesting The hatchlings were approximately $10 \mathrm{~cm}$ (S-V length) and $40 \mathrm{~g}$ (body mass). On five occassions, aggregations of 610 hatchlings were seen basking and moving about as a group. Because the hatchlings were extremely skittish and ran away from us before lengthy observations could be made, we were not able to compare the details of their behavior with that of other hatchling iguanines (Burghart et al.. 1977 and Greene et al. 1978).

During the nesting in October and November, one or two hawks were seen regularly in the vicinity of the nesting area, usually soaring high above the ground en route to some other part of the island: occasionally one or two would perch within or adjacent to the nesting area. During February, when hatchlings emerged from nests as many as nine hawks were seen perching and hunting in the area. At the peak time of hatching (mid February) there were typically 5-7 hawks in the area, preying on the hatchlings. By mid March, hawks were again only occasionally seen in the area.

\section{Experimental Methods}

The sprint rate (i.e. the maximum speed at which an animal will run over a short distance from a standstill) and its dependence on $T_{\mathrm{b}}$ was used as a measure of the physiological capability of lizards to a void predation. Data were collected on seven individuals whose body temperatures were varied between $15-40^{\circ} \mathrm{C}$ by using an ice bath to cool the animals and the sun to heat them. (Due to the difficult logistics of getting ice to the uninhabited island of Santa $\mathrm{Fe}$. we were unable to conduct this experiment after hatchlings emerged. Thus the data were collected from lizards ranging in size from 140-7,000 g but no newly emerged hatchlings were tested.) An elastic harness was fastened around the pectoral region of each iguana. and a long (approximately $4 \mathrm{~m}$ ) nylon cord leash was tied to the harness. This made it possible to recapture the iguanas after each sprint. Sprinting was induced by prodding and/or chasing the animals. Each iguana was allowed to sprint a distance of 5-15 body lengths. All iguanas were sprinted once and then allowed to rest for a period of several minutes before being sprinted again (iguanas could not be induced to sprint until they "recovered" from the previous sprint). After three consecutive sprints each iguana was allowed to rest at least one hour before being sprinted again. All lizards were sprinted at the same temperatures on different days to ensure that time and/or experience at sprinting did not influence the sprint rates of the lizards. Three or four people independently timed each sprint to the nearest $0.1 \mathrm{~s}$ with a stopwatch. The distances from the beginning to the end of the sprints were measured to the nearest $\mathrm{cm}$ with a tape. The sprint experiments were conducted on the rocky substrate typical of the island. Sprints that progressed into rocks and shrubs undoubtedly increased the variance in the sprint rates, but a more uniform substrate was not available in the field. The $T_{\mathrm{b}}$ of each iguana was measured to the nearest $0.5^{\circ} \mathrm{C}$ immediately after the sprint by using mercury thermometers (temperatures just before and just after sprints were not discernibly different). The sprint rate was calculated as $\mathrm{m} \mathrm{s}^{-1}$. The sprint rates for each individual were normalized to that individual's fastest sprint.

Observations were made during the month of February at the nesting area by one or two observers each day. The hawks usually attacked the hatchlings from a perch (tree or tall rockpile), but occasionally hunted by soaring over the area. In either case, an attack by a hawk or hawks was an obvious event because of the speed
Ind deliberateness of their stoop. After the hawk was on the ground, the observer moved closer to see if it had been successful at capturing fa hatchling.

In addition to noting whether or not the attack was "successful" (implying that the hawk captured its prey), the following information was recorded for each observed attack: time of day, air temperature $\left(T_{\mathrm{a}}\right)$ at approximately $2 \mathrm{~m}$ above the ground surface. temperature of the soil surface $\left(T_{\mathrm{s}}\right)$, and a qualitative description of the sky conditions (i.e.-sunny, cloudy, partly cloudy). Additional microclimatic data were taken at the nesting area on 12-13 January 1979. These data included air temperatures and wind speeds at five heights above the ground $(10,20,50.100$, and $200 \mathrm{~cm})$ : soil surface temperatures in the sun and shade: subsurface soil temperatures (at depths of 10,20 and $30 \mathrm{~cm})$ : hemispherical solar and thermal radiation. All temperatures were measured with a 28 gauge copper/constantan thermocouple wire, and the temperatures were read from a Wescor (Model TH-60) thermocouple thermometer. Wind speeds were measured simultancously with a Rimco miniature cup anemometer set. Hemispherical solar radiation wals measured with a Moll-Gorzinski solarimeter in conjuction with a Keithley microvoltmeter.

\section{Energy Exchange Model}

The body temperature of a hatchling lizard is determined by the thermal energy ofchange between the organism and its environment (Bakkenzand Gates 1975). An energy exchange model for a small lizard can be reduced to a simple energy balance when: (1) the metabolic heat production and evaporative heat loss rates are negligible relative to radiative and convective (Bartlett and Gates 1967. Porter et al. 1973, and Porter and James 1979); (2) the lizard's typical comportment is such that little of its body surface comes into contact with the substrate, thereby essentially elimating heat exchange by conduction from the substrate (see Bartlett and Gates 1967, Porter et al. 1973, and Porter and James 1979); and (3) the biological questions asked do not depend upon knowledge of the pattern or timing of change in body temperature while the lizard undergoes thermal transients (Spotila et 1. 1973), or when the time constant of body temperature change is negligible relative to the length of events in question (Riechert and Tracy 1975). (Our calculations of the time constant [see Porter et al. 1973] of a $40 \mathrm{~g}$ hatchling land iguana show that the time constant of a hatchling will rarely exceed $8 \mathrm{~min}$ ). We assumed that for the nature of the biological questions addressed, all three conditions could be adequately met. Thus, the energy balance model reduced to

$Q_{\mathrm{sw}}=\varepsilon \sigma\left(T_{\mathrm{L}}^{4}-T_{\mathrm{r}}^{4}\right)+h_{\mathrm{c}}\left(T_{\mathrm{L}}-T_{\mathrm{a}}\right)$

where $Q_{s w}$ is the absorbed short-wave solar radiation $\left(\mathrm{W} \cdot \mathrm{m}^{-2}\right)$ from all sources; $\left(T_{\mathrm{L}}^{4}-T_{\mathrm{r}}^{4}\right)$ is the net long-wave infrared radiation exchange $\left(\mathrm{W} \cdot \mathrm{m}^{-2}\right)$ between the lizard (whose surface temperature is $T_{\mathrm{L}}$ ) and the environment (with an average temperature $\left.T_{\mathrm{r}}\right) ; h_{\mathrm{c}}\left(T_{\mathrm{L}}-T_{\mathrm{s}}\right)$ is the convective heat exchange $\left(\mathrm{W} \cdot \mathrm{m}^{-2}\right)$ between the lizard and air; $h_{\mathrm{c}}$ is the convective heat transfer coefficient which depends upon the size of the animal and the speed and turbulence of the air passing over the surface of the animal: and $\varepsilon$ is the emissivity (and absorptivity) of the lizard to thermal radiation; and $\sigma$ is the Stephan-Boltzmann constant.

The convection coefficient, $h_{\mathrm{c}}$, was computed from a modification of the equation presented by Mitchell (1976)

$h_{\mathrm{c}}=K_{1} K_{2} V^{0.6} L^{-0.4}$

where $K_{1}$ is a constant determined by the shape of the organism (we used the (2) suggested [Mitchell 1976] $5.53 \mathrm{~J} \mathrm{~s}^{-0.4} \mathrm{~cm}^{-0.2}$ $\left.\mathrm{K}^{-1}\right) ; K_{2}$ is a constant accounting for the enhancement of convection due to turbulence in air (we fit an equation to the enhancement relation of Kowalski and Mitchell 1976: $K_{2}=171-$ 
$0.007(z / L)$, where $z$ is the height of the lizard above the ground (cm) and $L$ is the "characteristic dimension" of the lizard); $L$ is calculated as $L=m^{0.33}$ where $m$ is the mass of the animal $(\mathrm{g})$; and $V$ is the wind speed $(\mathrm{cm} / \mathrm{s})$.

Short wave radiation absorbed by hatchlings was calculated using the equations of Porter and Gates (1969) and Tracy (1976) and radiation measured from the sky. The proportion of a lizard's surface area receiving direct-beam solar radiation is the ratio of the lizard's silhouette area $\left(A_{s}\right)$ to the total surface area $(\mathrm{A})$. Total surface area was measured using the method of Porter and James (1979). Silhouette areas were measured with a planimeter from photographs of hatchlings. The ratio $A_{s} / A$ was greatest $(0.33)$ when the sun was directly overhead and the hatchlings were in a prostrate posture.

Scattered short-wave radiation from the sky and from the ground were each assumed to fall incidient on half of the total surface area of the lizard. The relative amounts of short-wave radiation measured with the pyranometer that was either scattered skylight or direct-beam radiation (Porter and Gates 1969) was calculated by the method of Tracy et al. (submitted).

The actual amount of radiation absorbed by the lizards is related to the absorptive property of the lizard's skin $(a)$. We measured the reflectivity of hatchling lizards using a reflectance sphere of the same size and view-port dimepsions as the reflectance sphere of a Beckman DK-2A spectroreflectometer. The sphere had three view-ports: one to allow admittance of a solar beam; one which would receive the direct solar beam and which was covered with the lizard's skin (intact lizards could be impressed over this port); and one from which reflected radiation could be measured (we used a Kettering Radiometer to measure the reflected radiation). The inside of the sphere was painted with $\mathrm{BaO}_{2}$ paint, and the radiation source used in the reflectance sphere experiments was normal clear-day solar radiation near midday in the Galapagos. The reflectance of a lizard's skin $\left(r_{s}\right)$ was computed as the ratio of radiation measured from the sphere with the lizard skin covering the test view-port relative to the radiation measured from the sphere when $\mathrm{BaO}_{2}$ reference covered the test port. Using this method, the solar absorptance of the hatchlings was computed to be $\left(1-r_{\mathrm{s}}\right)$ or 0.89 .

The proportion of radiation reflected from the substrate, $r$. was computed to be the ratio of energy measured with the pyranometer facing directly at the ground relative to the energy measured with the pyranometer facing directly toward the sun. The reflectance of the ground was measured to be 0.10 .

The average temperature of the radiative environment, $T_{\mathrm{r}}$, was taken to be the simple average of the temperature of the sky and the ground:

$T_{\mathrm{r}}=\left(T_{\mathrm{skv}}+T_{\mathrm{zrnd}}\right) / 2$

where the temperature of the ground was measured with a field thermometer. and the temperature of the sky was computed from the Brundt Equation (Gates 1962)

$T_{\text {sk! }}=\left[T_{3}^{4}\left\{0.44+20,08(\mathrm{e} / 100)^{0.5}\right]^{i / 4}\right.$

where $e$ is the vapor density of the air at screen height $(2 \mathrm{~m}$ from the ground.)

A summary of model parameters are given in Table 1 , and an example of the daily pattern of meteorological variables at the nesting sites is given in Fig. 1.

In order to simplify calculation of Eq. 1, we used a linear approximation of the net radiation term (see Campbell 1978). Thus, the temperature of the lizard could be computed from the modified energy balance as

$T_{\mathrm{L}}=\left[h_{\mathrm{c}} T_{\mathrm{a}}+\varepsilon \sigma 4 T_{\mathrm{a}}^{3} T_{\mathrm{r}}+Q_{\mathrm{sw}}\right] /\left[h_{\mathrm{c}}+\varepsilon \sigma 4 T_{\mathrm{a}}^{3}\right]$.

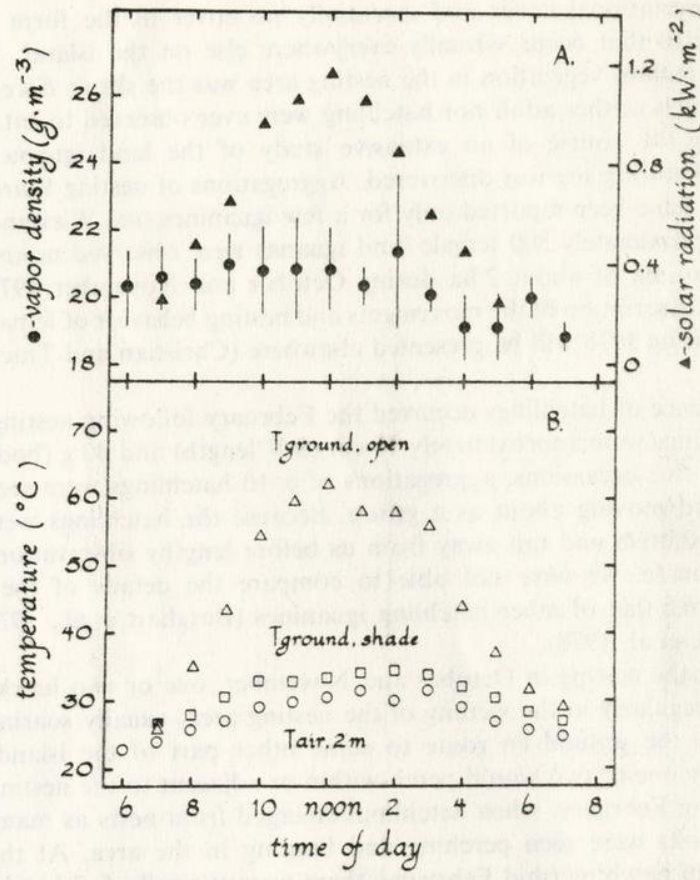

Fig. 1A, B. The daily pattern of meteorological variables for a typical day at the nesting site. A Means and standard deviations of vapor density measured on six days during the warm season when hatching occurs, and solar radiation measured on a single sunny day in mid January. B Temperatures of air, ground in the sun. and ground in the shade for a single sunny day in mid January. The data presented in (A) were used in computing lizard temperatures whereas (B) is presented only to indicate the general conditions of the warm season in which hatching occurred. Temperatures required for the simulation were measured at the site of each hawk attack

Using the energy balance equation we were able to predict $T_{\mathrm{b}}$ of each of the hatchlings involved in the 128 observed instances of hawk attacks. Since we did not know exactly what the hatchlings were doing immediately before an attack, we calculated, for each observation, $T_{\mathrm{b}}$ 's for two potential interactions with the environment: (1) the hottest interaction, in which we assumed that the hatchling was positioned in the open for some time before the attack occurred; and (2) the coolest case, in which we assumed that the hatchling had been in the shade of a shrub until immediately before the attack. Hatchlings on the nesting area were never seen climbing in shrubs, which would have resulted an even cooler interaction. (We did observe hatchlings climbing in Lantana shrubs after dispersal to other parts of the island.) The calculated body temperatures were compared with the sprint rate curve for the iguanas in order to make predictions about the ability of the hatchlings to sprint and thus escape from hawks.

\section{The Hypotheses}

Three behavioral activities were presumed to be important for the hatchlings upon emergence from their natal burrows. (1) dispersal from the nesting area to other parts of the island: (2) thermoregulation: and (3) avoidance of predators.

During February 1979 hatchlings dispersed from the nesting area within a day or two after emergence. The nesting area represented the least desirable habitat in which the hatchlings should remain because it (1) apparently contained no food. (2) had essentially no protective cover with which to avoid predators. 


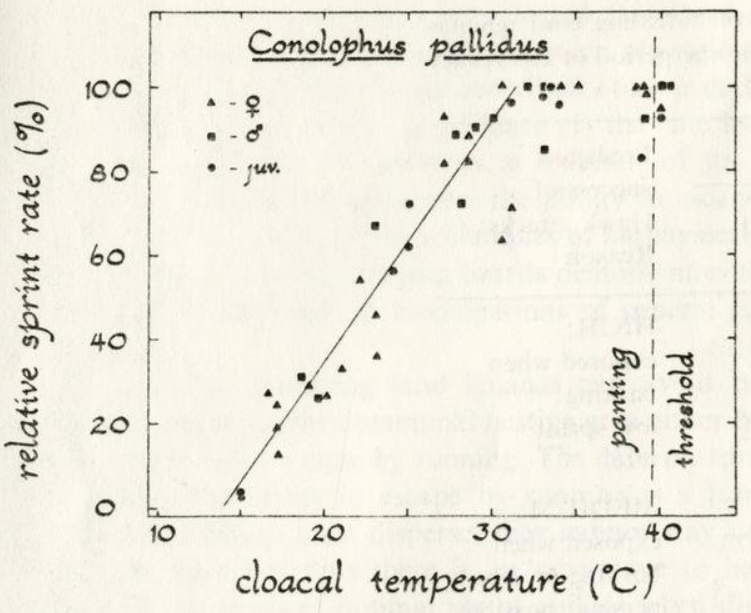

Fig. 2. Sprint rates of individual Galapagos land iguanas normalized to each individual's fastest sprint as a function of body temperature $\left(T_{\mathrm{b}}\right)$. The data are from 39 and $3 \delta$ adults and a $14 \mathrm{C} \mathrm{g}$ juvenile. The line is a least squares fit for the data where $T_{\mathrm{b}}<30^{\circ} \mathrm{C}$. The average panting threshold was $39.5^{\circ} \mathrm{C}$

and (3) it attracted a very high predator density. Thus, dispersal from the nesting area to other areas of the island with relatively more food and cover was a critically important activity for the hatchlings.

Thermoregulatory behavior appeared to be important to the hatchlings since the young lizards were observed to begin basking immediately after emerging from their nests. Regulation of body temperature is presumably necessary for the efficient digestion of residual yolk retained by hatchlings. Thermoregulation is also a significant influence on the efficiency with which a hatchling can avoid predation.

Predator avoidance was a key behavior because of the large concentration of hawks that exploited the annual emergence of hatchlings. We observed 128 attacks by hawks in which we could determine the success or failure of the hawk in capturing a hatchling. The hawks tended to attack when hatchlings were out in the open, apparently because the hatchlings were more conspicuous than when they remained motionless under shrubs, and also because of the difficulty and potential danger for the hawks in diving through shrubs to seize a hatchling.

\section{Results and Conclusions}

Normalized sprint rates as a function of body temperature are shown in Fig. 2. At the lower range of temperatures the sprint rate increases linearly with an increase in $T_{b}$. In order to estimate the mean maximal sprint rate from this linearly increasing portion we fit a linear equation by regression to all data collected at $T_{\mathrm{b}} \leqq 30^{\circ} \mathrm{C}$. The intercept of the equation with a line of $100 \%$ of maximal sprint was taken to be the $T_{\mathrm{b}}$ at which the mean maximal sprint occurred $\left(32^{\circ} \mathrm{C}\right)$. In the middle range of temperatures, the sprint rates level off, producing a plateau that extends at least to the panting threshold which is, on the average, $39.5^{\circ} \mathrm{C}$ (Christian et al. in prep.). Presumably, the sprint rates would drop off with a slight increase in $T_{\mathrm{b}}$ above the panting threshold. However, because Conolophus pallidus is an endangered species, we did not expose them to extreme heat stress.

All sprints of the iguanas were likely to be powered with anaerobic metabolism, and thus an oxygen debt was certainly accumulated with each sprint. It is likely that the lizards, then, were not at resting levels of lactate at each sprint (Pough 1980),
Table 1. List of parameters used in the energy budget model

\begin{tabular}{|c|c|c|c|}
\hline Symbol & Description & value & units \\
\hline$a$ & $\begin{array}{l}\text { absorptivity of hatchlings to } \\
\text { short-wave solar radiation }\end{array}$ & 0.89 & dimensionless \\
\hline$A_{\mathrm{S}} / A$ & $\begin{array}{l}\text { proportion of hatchling surface } \\
\text { area receiving solar radiation }\end{array}$ & 0.33 & dimensionless \\
\hline$\varepsilon$ & $\begin{array}{l}\text { thermal emissivity (and } \\
\text { absorptivity) of hatchlings }\end{array}$ & 0.95 & dimensionless \\
\hline$\kappa_{1}$ & $\begin{array}{l}\text { shape coefficient for convec- } \\
\text { tion coefficient of hatchlings }\end{array}$ & 5.53 & $\begin{array}{l}\text { J s } 0.4 \\
\mathrm{~cm} 0.2 \kappa \quad 1\end{array}$ \\
\hline$m$ & mass of hatchlings & 40.0 & g \\
\hline$r$ & $\begin{array}{l}\text { reflectivity of the substrate } \\
\text { (1) short-wave radiation }\end{array}$ & 0.10 & dimensionless \\
\hline $\begin{array}{l}\sigma \\
z\end{array}$ & $\begin{array}{l}\text { Stephan-Boltzmann Constant } \\
\text { height of the lizard above the } \\
\text { substrate }\end{array}$ & $\begin{array}{l}5.67 \times 10 \times \\
1.5\end{array}$ & $\begin{array}{l}W \mathrm{~m}=K^{+} \\
\mathrm{cm}\end{array}$ \\
\hline
\end{tabular}

but (a) the rest periods probably allowed the lizards to recover sufficiently to sprint at maximal levels, and (b) the sprints were probably conducted at lactate levels typical of those for a free ranging lizard during dispersal. Furthermore, we compared the sprint rates of the first sprint of the day for each individual to the sprint rates of the individuals (at the same body temperature) after they had been sprinted an average of nine times (with rest periods as described earlier), and the sprint rates were statistically identical $\bar{X}=2.21 \pm 0.26 \mathrm{~m} / \mathrm{s}$ for the first sprints and $\bar{X}=2.01 \pm 0.56 \mathrm{~m} / \mathrm{s}$ for the ninth sprint). Moreover, we have collected data on another iguanid, Dipsosaurus dorsalis (Tracy unpublished data), which suggests that the functional relationship between relative sprint-rate and body temperature is the same for moderately exhausted animals and for completely fresh animals. Thus, it seems reasonable to assume that our sprint experiments reflect the influence of body temperature on the relative locomotory ability of hatchlings to avoid predators.

The relationship between sprint rate and $T_{\mathrm{b}}$ was then used to define thermal environments in terms of the physiological state of the lizards as determined by the thermal environmental interaction (Mason and Langenheim 1957). Three environments were outlined: $\mathrm{COOL}$, where $T_{\mathrm{b}}<32^{\circ} \mathrm{C}$; WARM, where $32 \leqq$ $T_{\mathrm{b}} \leqq 40^{\circ} \mathrm{C}$; and HOT, where $T_{\mathrm{b}}>40\left(40^{\circ} \mathrm{C}\right.$ was selected as the transition between a WARM and HOT environment because at $40^{\circ} \mathrm{C}$ lizards conspicuously pant, presumably to lower their temperature).

A pair of $T_{\mathrm{b}}$ 's was calculated for each hatchling observed to be attacked by a predator; one assumed the hatchling was as cool as possible for that time of the day and day of the year, and the other assumed the hatchling was in the warmest possible microclimate. The first two columns of Table 2 present this dual-limit characterization of the thermal environment. Thus, early in the morning and late in the evening the environmental conditions were COOL-COOL (first row, Table 2) because it was impossible for a hatchling to have a $T_{\mathrm{b}} \geqq 32^{\circ} \mathrm{C}$ during those periods. Later in the morning. conditions under the shrubs were COOL, but out in the open it was WARM (second row, Table 2). During the middle of the day conditions were WARM under the shrubs and HOT in the open (third row). Other permutations are theoretically possible (i.e. COOLHOT or HOT-HOT), but these thermal environments did not exist on Santa Fe during February 1979.

Given these environmental conditions, we made prediction? concerning the three behaviors discussed above (thermoregulatory, predator avoidance, and dispersal) (Table 2). Predictions for 
Table 2. Summary of thermal envirenmental conditions, predicted behaviors of hatchling land iguanas and predicted suceess of Galapagos Hawks preying on iguana hatchlings during the period of emergence of iguanas from their natal burrows in liebruary, 1979

\begin{tabular}{|c|c|c|c|c|c|}
\hline \multicolumn{2}{|c|}{ Environmental C'onditions } & \multicolumn{3}{|c|}{ Predicted Behaviors } & \multirow{2}{*}{$\begin{array}{l}\text { Predicted } \\
\text { success of } \\
\text { Hawk attacks: } \\
\text { Reason }\end{array}$} \\
\hline $\begin{array}{l}\text { Under shrubs } \\
\text { (Predicted } T_{\mathrm{h}} \text { ) }\end{array}$ & $\begin{array}{l}\text { In Open } \\
\text { (Predicted } T_{\mathrm{b}} \text { ) }\end{array}$ & $\begin{array}{l}\text { Thermo- } \\
\text { regulatory }\end{array}$ & $\begin{array}{l}\text { Predator } \\
\text { Avoidance }\end{array}$ & Dispersal & \\
\hline $\begin{array}{l}\text { COOL } \\
\left(T_{\mathrm{b}}<32^{\circ}\right)\end{array}$ & $\begin{array}{l}\text { COOL } \\
\left(T_{\mathrm{b}}<32^{\circ}\right)\end{array}$ & $\begin{array}{l}\text { bask in } \\
\text { open or } \\
\text { remain } \\
\text { under } \\
\text { shrubs }\end{array}$ & $\begin{array}{l}\text { stay } \\
\text { under } \\
\text { shrubs }\end{array}$ & $\begin{array}{l}\text { no } \\
\text { dispersal }\end{array}$ & $\begin{array}{l}\text { HIGH: } \\
\text { exposed when } \\
\text { basking: } \\
\text { low sprint } \\
\text { rate }\end{array}$ \\
\hline $\begin{array}{l}\mathrm{COOL} \\
\left(T_{\mathrm{b}}<32^{\circ}\right)\end{array}$ & $\begin{array}{l}\text { WARM } \\
\left(T_{\mathrm{b}}=32^{\circ}-40^{\circ}\right)\end{array}$ & $\begin{array}{l}\text { bask } \\
\text { in open }\end{array}$ & $\begin{array}{l}\text { stay } \\
\text { under } \\
\text { shrubs }\end{array}$ & $\begin{array}{l}\text { dispersal } \\
\text { when warm }\end{array}$ & $\begin{array}{l}\text { MEDIUM: } \\
\text { exposed when } \\
\text { basking or dis- } \\
\text { persing: possibly } \\
\text { low sprint rateb }\end{array}$ \\
\hline $\begin{array}{l}\text { WARM } \\
\left(T_{\mathrm{b}}=32^{\circ}-40^{\circ}\right)\end{array}$ & $\begin{array}{l}\text { HOT } \\
\left(T_{\mathrm{b}}>40^{\circ}\right)\end{array}$ & $\begin{array}{l}\text { stay } \\
\text { under } \\
\text { shrubs }\end{array}$ & $\begin{array}{l}\text { stay } \\
\text { under } \\
\text { shrubs }\end{array}$ & dispersal & $\begin{array}{l}\text { LOW: } \\
\text { exposed only } \\
\text { when dispersing: } \\
\text { high sprint rate }\end{array}$ \\
\hline
\end{tabular}

basking should only occur if $T_{\mathrm{b}}$ can become higher as a result.
" low sprint rate would occur if a hatchling just began basking and still had a low $T_{\mathrm{b}}$.
basking is never required in order to have maximal sprint rate.

$$
y^{2}
$$

different behaviors often conflicted with one another. For example, the prediction for predator avoidance (Table 2) is always to stay under the shrubs (i.e. to remain inconspicuous), which conflicts with the predictions for thermoregulation during cooler conditions and for dispersal during warmer conditions. If prevailing conditions were WARM-HOT, the prediction for thermoregulation would be to stay under the shrubs since a hatchling there could maintain an optimal $T_{\mathrm{b}}$ (in terms of sprint rate), and may, in fact, encounter a lethal $T_{\mathrm{b}}$ out in the sun. However, the hatchlings must disperse from the nesting site to areas with more food and cover. Dispersak is predicted to occur during times when WARM or HOT conditions prevail (resulting in a $T_{\mathrm{b}}>32^{\circ} \mathrm{C}$ ). During these periods hatchlings could attain capacity for maximal sprint rate under the protection of concealing cover, without incurring the risks of basking in the open. Thus, the hatchlings should be able to disperse from the nesting area with a maximal sprint rate and with minimal risk of predation.

The last column of Table 2 shows the predicted success of hawk attacks for each of the sets of environmental conditions. During COOL-COOL times of the day, the predicted success of the hawks is high since the hatchlings would always have a suboptimal sprint rate, and they would be exposed to predators during any basking. In COOL-WARM conditions the prediction is of intermediate success for the hawks. Under these conditions the hatchlings could have a low sprint rate if they remained under the shrubs or if they just began basking. or they could have a high sprint rate if they had been basking long enough to attain an elevated temperature. Hatchlings would be exposed to predation when basking and when dispersing. The predicted success of the hawks is low during the WARM-HOT times of day because the hatchlings would have a high sprint rate without exposing themselves during basking, and thus they need only be exposed while dispersing (they can reach optimal $T_{\mathrm{b}}$ under the protection of the shrubs when it is WARM under the shrubs).

Table 3 shows the observed success of hawk attacks for the three combinations of thermal environments. The hawks were successful at capturing a hatchling in $67 \%$ of their attacks when
Table 3. Summary of predictions of hawk success at predation on hatching iguanas and measured success percentages

\begin{tabular}{|c|c|c|c|c|}
\hline $\begin{array}{l}\text { Environmental } \\
\text { Conditions }\end{array}$ & $\begin{array}{l}\text { \% of Typical Day } \\
\text { Day In Which } \\
\text { Described Environ- } \\
\text { mental Conditions } \\
\text { Existed }\end{array}$ & $\begin{array}{l}\text { Predicted } \\
\text { Success } \\
\text { of Hawk } \\
\text { Attacks }\end{array}$ & $\begin{array}{l}\text { Observed } \\
\text { Success } \\
\text { of Hawk } \\
\text { Attacks }\end{array}$ & $\begin{array}{l}\text { Sample } \\
\text { Size }\end{array}$ \\
\hline COOL-COOL & $29 \%$ & $\mathrm{HIGH}$ & $67 \%$ & 21 \\
\hline COOL-WARM & $21 \%$ & MEDIUM & $46 \%$ & 24 \\
\hline WARM-HOT & $50 \%$ & LOW & $19 \%$ & 83 \\
\hline
\end{tabular}

the hatchlings were unable to attain a $T_{\mathrm{b}} \geqq 32^{\circ} \mathrm{C}$. This compares to a $46 \%$ success during WARM-HOT times when the hatchlings could have had either an optimal or suboptimal sprint rate depending on which microclimate they occupied before the attack. During periods when the hatchlings had the ability to sprint maximally $\left(40>T_{\mathrm{b}} \geqq 32^{\circ} \mathrm{C}\right.$ ) without basking in the open, the hawks were successful in only $19 \%$ of their attacks. This relationship between predicted $T_{\mathrm{b}}$ of the hatchlings and the success of the hawk attacks is significant $\left(\chi^{2}=19.87 . P<0.001\right)$.

A large portion of the observed hawk attacks occurred during periods in which WARM-HOT conditions existed (Table 3). In part, this can be explained by the fact that during $50^{\circ}$ of a typical day, these conditions existed. However, the proportion of attacks during these periods is significantly higher $\left(\chi^{2}=11.56\right.$; $P<0.005)$ than would be expected given the percentages of a typical day in which the different environmental conditions exist. If we can assume that the movements of dispersing hatchlings induce attacks by hawks. then this may provide indirect evidence that a significant amount of dispersal occurred during WARMHOT conditions as was predicted in Table 2 on the basis of sprint rate data. A counter alternative is that at times when hatchlings are significantly better at escaping predators, predators need to make more attacks on hatchlings in order to satiate themselves. 
Huey and Stevenson (1979) have noted that there is a gap in our knowledge of the interactions between physiological performance and ecology. This study contributes to our understanding of this aspect by providing evidence (1) that the locomotor ability of an ectothermic lizard is a function of its $T_{\mathrm{b}}$, and (2) that this relationship influences the ability to escape predators. In addition, the use of the techniques of biophysical ecology to predict the $T_{\mathrm{b}}$ 's of free ranging lizards demonstrates the value of these analytical tools in investigations of general ecological importance.

In summary, hatchling land iguanas can avoid predation while they remain in the communal nesting area either by hiding under shrubs or by escape by running. The data on sprint rates suggest that the ability to escape by running is a function of $T_{\mathrm{b}}$. Since hatchlings must disperse, they cannot stay under the shrubs all the time; thus there is an advantage to having an optimal $T_{\mathrm{b}}$ (in terms of optimal sprint ability) when dispersing. We therefore conclude that the success of hawk attacks under different environmental conditions demonstrate that the physical environment, as mediated through the physiological response to $T_{\mathrm{b}}$, significantly influences the survival of hatchling Galapagos land iguanas.

Acknowledgments. We wish to thank the Galapagos National Park Service and the Charles Darwin Research Station for the permission and logistical support for this study. Many months of valuable assistance in gathering data in the field were provided by Sylvia Harcourt, Janet Shur. and David Socha. Mike McGovern assisted with the sprint rate experiments. This study could not have been accomplished with out the help of these people, and to them we are deeply indebted. Dr. W. Porter contributed logistic support as well as stimulating discussions of ideas. Porter also measured the surface area and reflectances of hatchings, and his help is gratefully acknowledged. We would like to acknowledge the generous loans and gifts of equipment by Dean Cilly of Holubar Inc. : Eureka Tents: and by Warren P. Porter. This is contribution No. 279 of the Charles Darwin Foundation for the Galapagos Islands.

\section{References}

Bakken GS, Gates DM (1975) Heat transfer analysis of animals: some implications for field ecology, physiology and evolution. In: D M Gates and RB Schmerl (eds). Perspectives in Biophysical Ecology, Springer, Berlin Heidelberg New York pp. 255290

Bartlett PN, Gates DM (1967) The energy budget of a lizard on a tree trunk. Ecology 48:315-322

Burghardt GM. Greene HW. Rand AS (1977) Social behavior in juvenile green iguanas: life at a reptile rookery. Science 195:689-691

Campbell (GS (1978) An introduction to Environmental Biophysics. Springer. Berlin. Heidelberg New York p 159

Christian KA. Tracy CR (1981) Reproductive behavior of Galapagos Land Iguanas (Comelophus pallidus) on Isla Santa Fe, Galapagos. In: Iguanas of the World: Behavior. Ecology, and Conservation. GM Burghardt and AS Rand (eds), Garland STPM Press. New York

Curio E (1976) The ethology of predation. Springer. Berlin Heidelberg New lork p 250
deVries T (1973) The Galapagos Hawk: an eco-geographical study with special reference to its systematic position. Vrije Universiteit te Amsterdam.

Fox SF (1978) Natural selection on behavioral phenotypes of the lizard Uta stanshuriana. Ecology $59: \$ 34 \$ 47$

Gates DM (1962) Energy exchange in the biosphere. Harper and Row. New York

Greene HW, Burghardt GM. Dugan BA Rand AS (1978) Predation and the defensive behavior of green iguanas (Reptilia, Lacertilia. Iguanidae). J Herp 12(2): 169176

Greenwald OE (1974) Thermal dependence of striking and prey capture by gopher snakes. Copeia 1974:141 148

Heatwole H (1976) Reptile Ecology. U of Queenland Press. St Lucia p 178

Huey RB, Slatkin M (1976) Costs and benefits of lizard thermoregulation. Quart Rev Biol 51:363 384

Huey RB. Stevenson RD. Integrating thermal physiology and ecology of ectotherms: a discussion of approaches. Amer Zool 19:357 366

Kowalski GJ. Mitchell JW (1976) Heat transfer from spheres in the naturally turbulent, outdoor envrionment. J Heat transf 98 (4):649 653

Mason HL, Langenheim JH (1957) Language analysis and the concept environment. Fcology $38: 3,30 \quad 340$

Mitchell JW (1976) Heat transfer from spheres and other animal forms. Biophysical J 16:561 56\%?

Porter WP. Mitchell JW. Begknian WA and DeWitt CB (1973) Behavioral implications of mechanistic ecology: Thermal and behavioral modeling of desert ectotherms and their microenvironment. Oecologia $13: 1 \quad 54$

Porter WP. Gates DM (1969) Thermodynamic equilibria of animals with environment. Ecol Monogr. 39:245 270

Porter WP. James FC (1979) Behavioral implications of mechanistic ecology 11: The African Rainbow Lizard Agama agama. Copeia $1979: 594619$

Porter WP. Mitchell JW. Bêckman WA. Tracy CR (1975) Environmental constraints on some predator-prey interactions. In: Perspectives of biophysical ecology. DM Gates and RB Schmerl (eds), p. 347 364. Springer. Berlin Heidelberg New York

Porter WP. Tracy CR (1974) Modeling the effects of temperature changes on the ecology of the garter snake and leopard frog. In: Thermal Ecology, J W Gibbons and RR Shritz (eds), US At Energy Comm Rep CONF-730505. p 670 p 594609

Pough FH (1980) The advantages of ectothermy for tetrapods. Am Nat 115:92-112

Rand AS (1964) Inverse relationship between temperature and shynes in the lizard Anolis lineatopus. Ecology 45:863 864

Riechert SE. Tracy CR. Thermal balance and prey availability: bases for a model relating web-site characteristics to spider reproductive success. Ecology $56: 265284$

Spotila JR, Lommen PW, Bakken GS, Gates DM (1973) A mathematical model for body temperatures of large reptiles: implications for dinosaur ecology. Am Nat 107:391 404

Tracy CR (1976) A model of the dynamic exchanges of water and energy between a terrestrial amphibian and its environment. Ecol Monogr 46:293 326

Wiewandt TA (1981) Nesting patterns of iguanine lizards. In: Iguanas of the world: Behavior, Ecology, and Conservation. GM Burghardt and AS Rand (eds) Garland STPM Press New York

Received August 4. 1980 